\title{
Deposition-Parameter-Determined Resistive Switching Characteristics in $\mathrm{TiO}_{x} / \mathbf{P b}\left(\mathbf{Z r}_{0.52} \mathrm{Ti}_{0.48}\right) \mathrm{O}_{3}$ Bilayers
}

\author{
Xiaoyu Zhou, ${ }^{1,2,3}$ Yuan Luo, ${ }^{1,2,3}$ Aidong Li, ${ }^{1,2,3}$ and Di Wu ${ }^{1,2,3}$ \\ ${ }^{1}$ National Laboratory of Solid State Microstructures, Nanjing University, Nanjing 210093, China \\ ${ }^{2}$ Department of Materials Science and Engineering, College of Engineering and Applied Sciences, Nanjing University, \\ Nanjing 210093, China \\ ${ }^{3}$ Collaborative Innovation Center of Advanced Microstructures, Nanjing University, Nanjing 210093, China
}

Correspondence should be addressed to Di Wu; diwu@nju.edu.cn

Received 15 March 2015; Accepted 18 May 2015

Academic Editor: Ying Li

Copyright (C) 2015 Xiaoyu Zhou et al. This is an open access article distributed under the Creative Commons Attribution License, which permits unrestricted use, distribution, and reproduction in any medium, provided the original work is properly cited.

$\mathrm{Pb}\left(\mathrm{Zr}_{0.52} \mathrm{Ti}_{0.48}\right) \mathrm{O}_{3}(\mathrm{PZT})$ ferroelectric thin films were deposited epitaxially, by pulsed laser deposition, on $(001) \mathrm{SrTiO}_{3}$ substrates buffered with $\mathrm{La}_{0.7} \mathrm{Sr}_{0.3} \mathrm{MnO}_{3}$ (LSMO) electrodes. Amorphous $\mathrm{TiO}_{x}$ thin films were deposited on top of $\mathrm{PZT}$ at various temperatures and oxygen chamber pressures. Bipolar resistive switching characteristics of $\mathrm{Pt} / \mathrm{TiO}_{x} / \mathrm{PZT} / \mathrm{LSMO}$ heterostructures are found to vary with $\mathrm{TiO}_{x}$ deposition parameters, from an interface controlled ferroelectric diode behavior to a bulk-controlled conductive filament behavior. The observations are discussed in terms of the concentration and migration of oxygen vacancies in the $\mathrm{TiO}_{x}$ layer.

\section{Introduction}

Although memories based on FLASH techniques are ubiquitous nowadays, novel nonvolatile memories, such as phase-change memories, resistive switching memories, and magnetic and ferroelectric tunnel-junction-memories, have attracted much attention recently to achieve lower power consumption and higher data storage density. Among these emerging memories proposed, resistive switching memories have shown advantages such as scalability $[1,2]$, high speed [3], long data retention, high-endurance [4], and low energy consumption [5].

Resistive switching behaviors have been reported in a number of materials due to various mechanisms. In binary transition metal oxides, resistive switching has been extensively studied and modulations on filamentary conduction have been widely accepted. Formation and rupture of conductive $\mathrm{TaO}_{1-x}$ filaments, responsible for resistive switching in $\mathrm{Pt} / \mathrm{SiO}_{2} / \mathrm{a}-\mathrm{Ta}_{2} \mathrm{O}_{5-x} / \mathrm{a}-\mathrm{TaO}_{2-x} / \mathrm{Pt}$ heterostructures, have been directly observed by transmission electron microscopy [6]. Salaoru et al. and Bousoulas et al. proposed that concentration and distribution of oxygen vacancies have a great impact on the diameter of the conducting filaments and hence the operation of $\mathrm{TiO}_{2-x}$-based memory devices $[7,8]$. However, other resistive switching mechanisms have also been proposed. For example, resistive switching in $\mathrm{ZrO}_{2}$ has been ascribed to space charge limited currents modulated by $\mathrm{Zr}^{+}$traps [9]. Electrically induced modulations on oxide/electrode interface barriers may also result in resistive switching $[10,11]$. Although such modulations can be achieved through electric-field-driven migrations of charged defects, ferroelectric switching provides a unique modulation mechanism in this respect, the switchable ferroelectric diode behavior, as first observed in $\mathrm{BiFeO}_{3}$-based devices $[12,13]$. In these devices, Schottky barriers are formed at both interfaces and the barrier heights can be switched to a high or a low level as a response to the switched bound charges at the interface due to ferroelectric switching.

In this report, we show that resistive switching in $\mathrm{Pt} /$ $\mathrm{Pb}\left(\mathrm{Zr}_{0.52} \mathrm{Ti}_{0.48}\right) \mathrm{O}_{3}$ (PZT)/Pt devices can be tuned from a ferroelectric diode behavior to an oxygen vacancy controlled behavior by inserting a $\mathrm{TiO}_{x}$ interfacial layer between PZT and Pt top electrodes. Deposition parameters of the $\mathrm{TiO}_{x}$ interfacial layer, such as substrate temperature and oxygen chamber pressure, are demonstrated significant to the observed resistive switching behavior. 


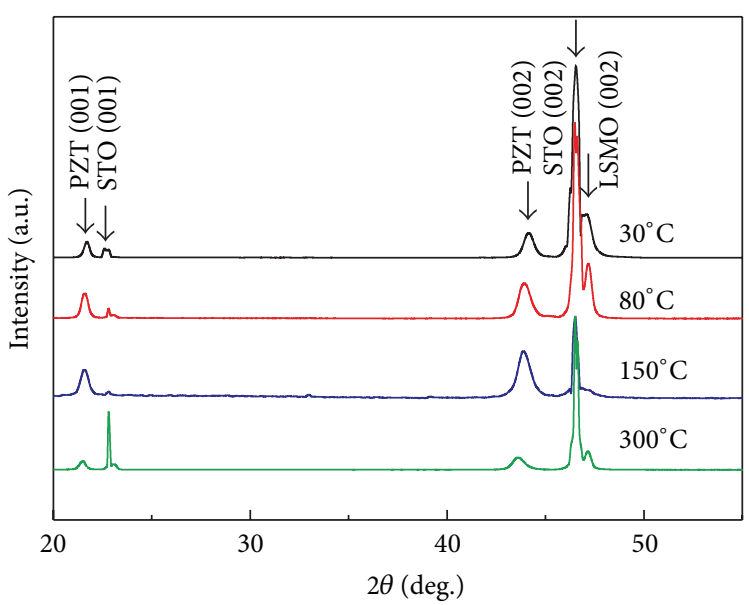

(a)

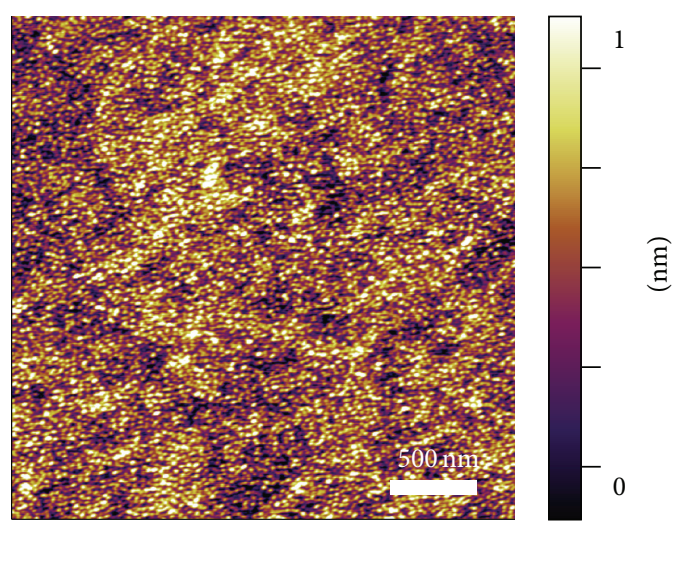

(b)

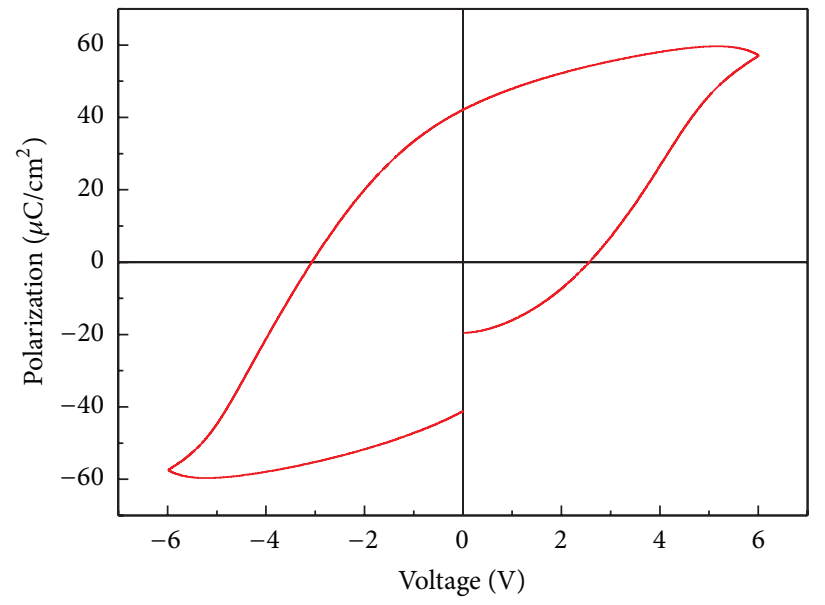

(c)

FIgURE 1: (a) XRD patterns of $\mathrm{TiO}_{x} / \mathrm{PZT} / \mathrm{LSMO} / \mathrm{STO}$ heterostructures, in which the $\mathrm{TiO}_{x}$ layers were deposited in $2.0 \mathrm{~Pa}$ oxygen at various temperatures from 30 to $300^{\circ} \mathrm{C}$; (b) typical surface morphology of $\mathrm{TiO}_{x} / \mathrm{PZT} / \mathrm{LSMO} / \mathrm{STO}$ heterostructures; (c) hysteresis loop of a $50 \mathrm{~nm}$ thick PZT film.

\section{Experimental Section}

The heterostructures studied were deposited by pulsed laser deposition (Adnano Corp.). A Coherent CompexPro 205F $\mathrm{KrF}$ excimer laser was employed, with an output of $248 \mathrm{~nm}$ at $2.0 \mathrm{~Hz}$ repetition. The energy flux was estimated as $1.0 \mathrm{~J} / \mathrm{cm}^{2}$ for all the depositions. $\mathrm{La}_{0.7} \mathrm{Sr}_{0.3} \mathrm{MnO}_{3}$ (LSMO) electrodes were deposited epitaxially on (001) $\mathrm{SrTiO}_{3}$ (STO) singlecrystal substrates at $800^{\circ} \mathrm{C}$. Then $\mathrm{Pb}\left(\mathrm{Zr}_{0.52} \mathrm{Ti}_{0.48}\right) \mathrm{O}_{3}(\mathrm{PZT})$ were deposited on top of LSMO at $650^{\circ} \mathrm{C}$. For both LSMO and PZT depositions, the oxygen partial pressure was kept at $13.3 \mathrm{~Pa}$. $\mathrm{TiO}_{x}$ films were deposited either in background vacuum $\left(10^{-5} \mathrm{~Pa}\right)$ or in $2.0 \mathrm{~Pa}$ oxygen pressure at various temperatures from 30 to $300^{\circ} \mathrm{C}$. The thicknesses of LSMO, PZT, and $\mathrm{TiO}_{x}$ layers are 40,50, and $50 \mathrm{~nm}$, respectively, as calibrated using a Zeiss Ultra 55 field emission scanning electron microscope. For electrical measurements, $\mathrm{Pt}$ top electrodes, $100 \mu \mathrm{m}$ in diameter, were sputter-deposited through a shadow mask.
Crystal structures of the multilayers were characterized by X-ray diffraction (XRD) using a Rigaku ULTIMA-III diffractometer with a $\mathrm{Cu} \mathrm{K} \alpha$ radiation. Surface topography was studied using an Asylum Research Cypher atomic force microscope (AFM) in contact mode. Electrical measurements were conducted using a Keithley 2400 source-measure unit. Voltage was applied to the Pt top electrodes and the bottom LSMO electrodes were always grounded. Chemical analysis was carried out ex situ by X-ray photoelectron spectroscopy (XPS) using a Thermo Fisher K-Alpha spectrometer equipped with an $\mathrm{Al} \mathrm{K} \alpha(1486.7 \mathrm{eV}) \mathrm{X}$-ray source.

\section{Results and Discussion}

Figure 1(a) shows XRD patterns of $\mathrm{TiO}_{x} / \mathrm{PZT} / \mathrm{LSMO}$ heterostructures deposited on (001) STO substrates. The $\mathrm{TiO}_{x}$ layers were deposited in $2.0 \mathrm{~Pa}$ oxygen at various temperatures from 30 to $300^{\circ} \mathrm{C}$. Only diffraction peaks from (001) crystalline planes of PZT and LSMO are observed, 


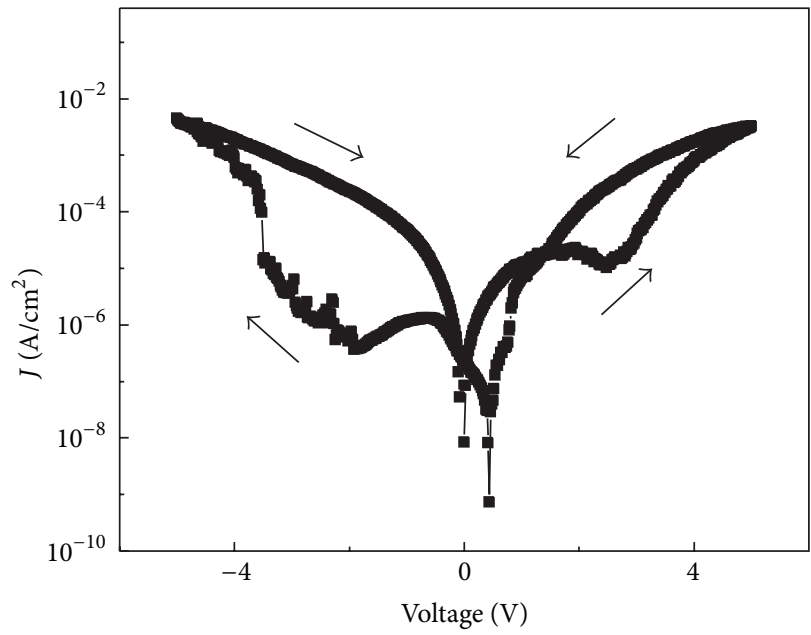

(a) PZT

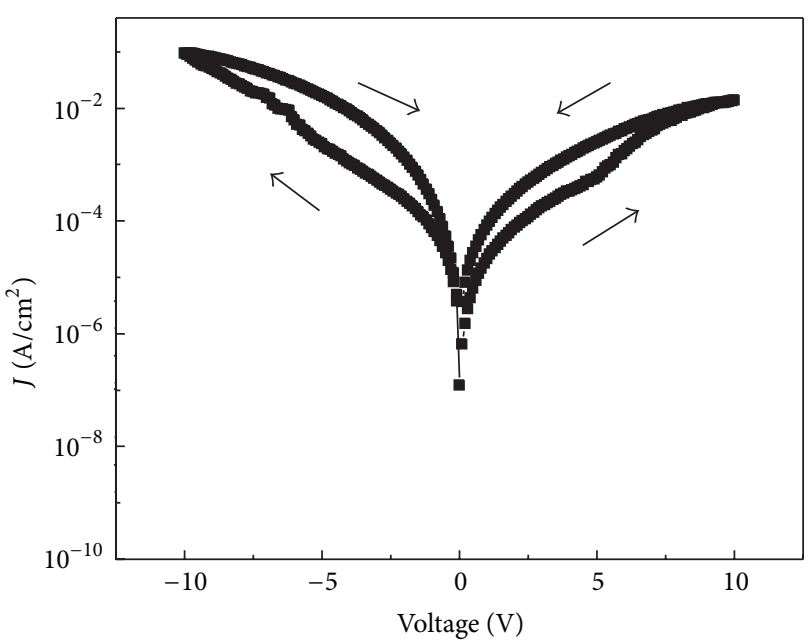

(c) $\mathrm{TiO}_{x}\left(2.0 \mathrm{~Pa}, 80^{\circ} \mathrm{C}\right) / \mathrm{PZT}$

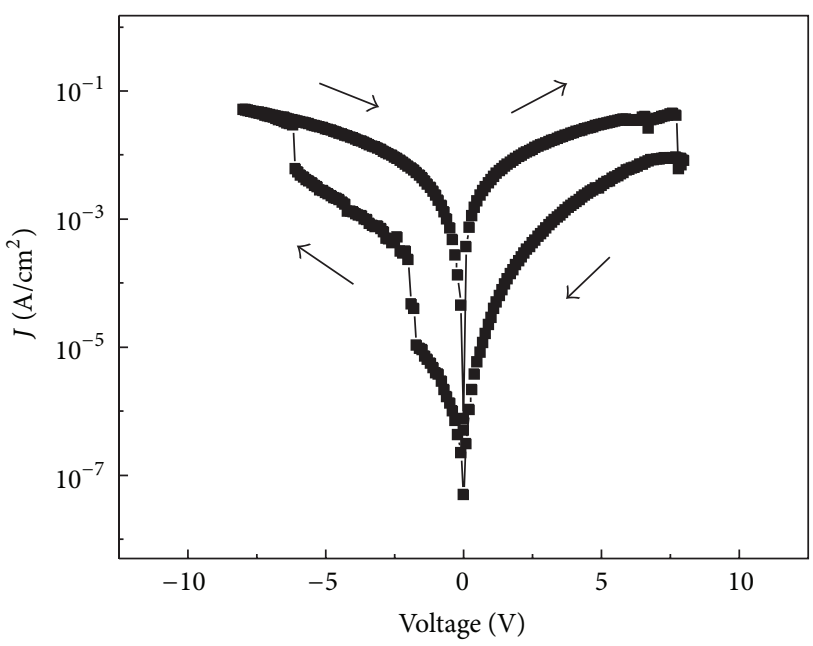

(e) $\mathrm{TiO}_{x}\left(2.0 \mathrm{~Pa}, 300^{\circ} \mathrm{C}\right) / \mathrm{PZT}$

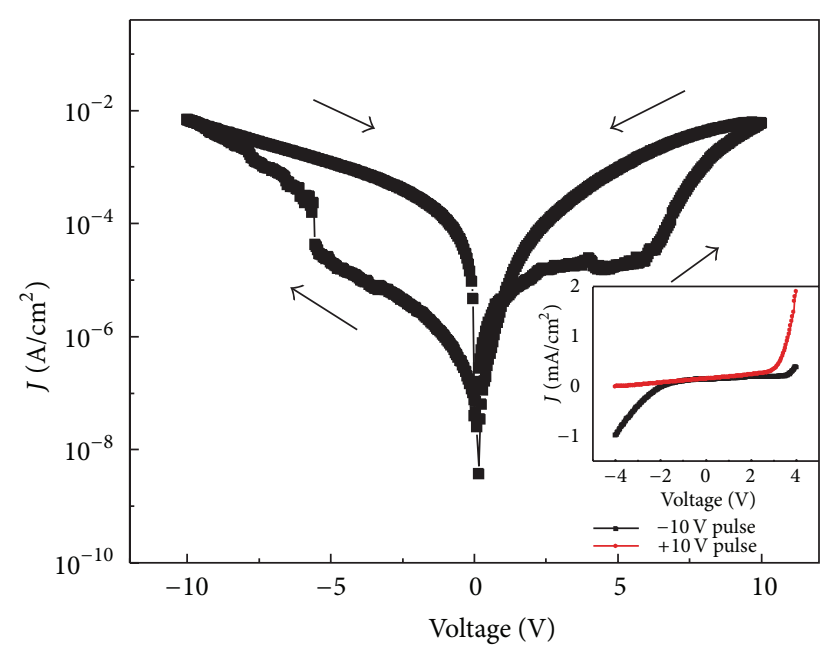

(b) $\mathrm{TiO}_{x}\left(2.0 \mathrm{~Pa}, 30^{\circ} \mathrm{C}\right) / \mathrm{PZT}$

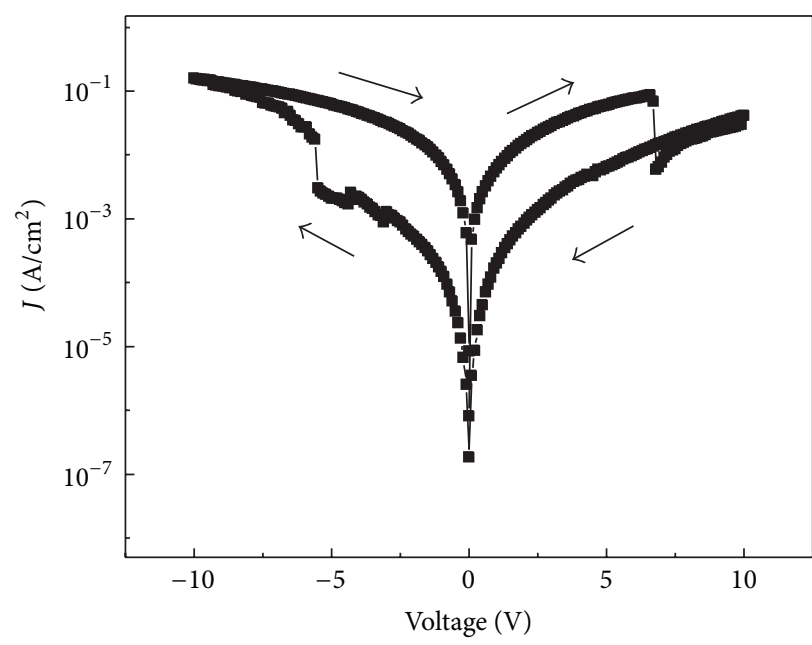

(d) $\mathrm{TiO}_{x}\left(2.0 \mathrm{~Pa}, 150^{\circ} \mathrm{C}\right) / \mathrm{PZT}$

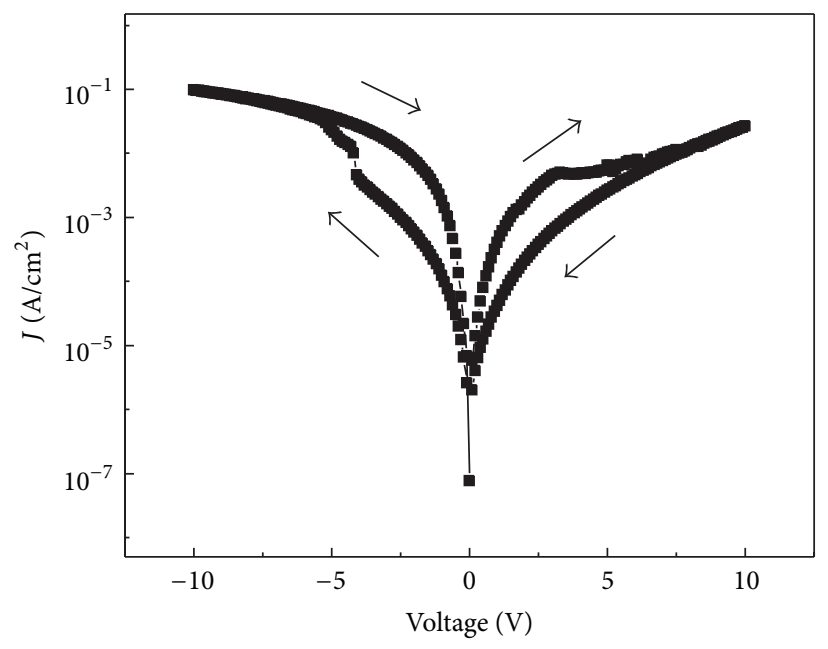

(f) $\mathrm{TiO}_{x}\left(2.0 \mathrm{~Pa}, 30^{\circ} \mathrm{C}\right)$

Figure 2: $I$ - $V$ curves of $\mathrm{Pt} / \mathrm{PZT} / \mathrm{LSMO}(\mathrm{a}), \mathrm{Pt} / \mathrm{TiO}_{x} / \mathrm{PZT} / \mathrm{LSMO}$ in which the $\mathrm{TiO}_{x}$ layer is deposited at 30 (b), 80 (c), 150 (d), and $300^{\circ} \mathrm{C}(\mathrm{e})$ in $2.0 \mathrm{~Pa}$ oxygen pressure and $\mathrm{Pt} / \mathrm{TiO}_{x} / \mathrm{LSMO}$ in which the $\mathrm{TiO}_{x}$ layer is deposited at $30^{\circ} \mathrm{C}$ in $2.0 \mathrm{~Pa}$ oxygen pressure (f). The arrows indicate the voltage sweeping directions. The inset in (b) shows the $I-V$ curves measured after the PZT layer is poled to opposite directions. 


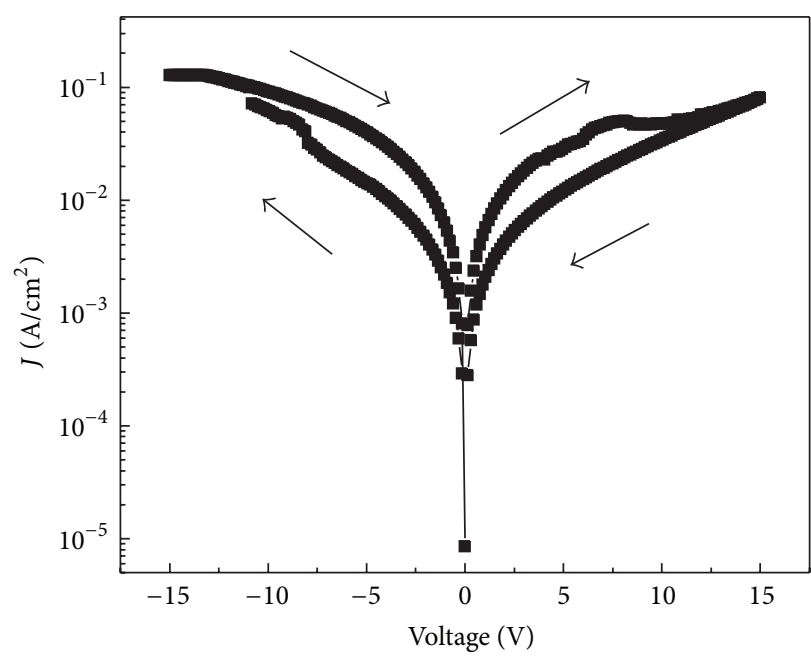

(a) $\mathrm{TiO}_{x}\left(10^{-5} \mathrm{~Pa}, 30^{\circ} \mathrm{C}\right) / \mathrm{PZT}$

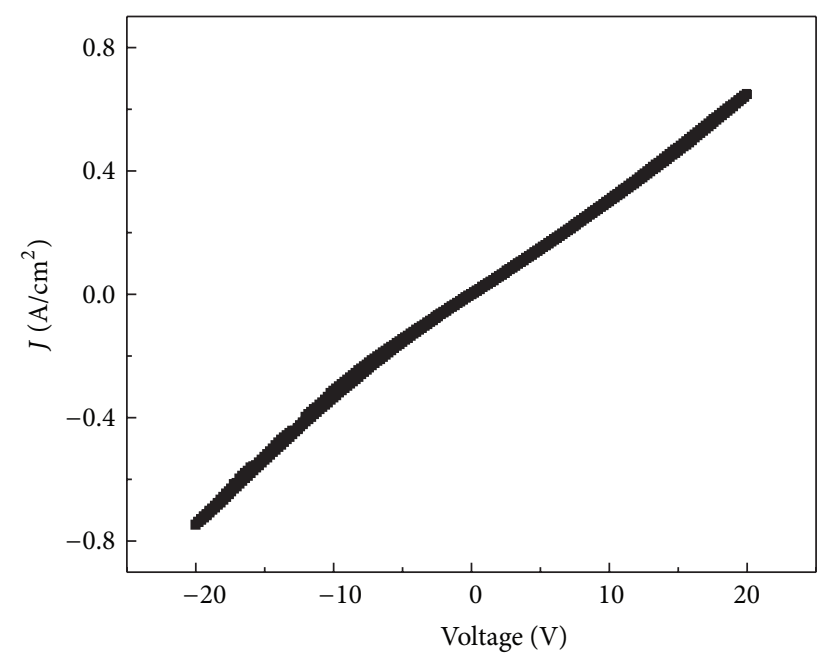

(b) $\mathrm{TiO}_{x}\left(10^{-5} \mathrm{~Pa}, 150^{\circ} \mathrm{C}\right) / \mathrm{PZT}$

Figure 3: $I-V$ curves of $\mathrm{Pt} / \mathrm{TiO}_{x} / \mathrm{PZT} / \mathrm{LSMO}$ in which the $\mathrm{TiO}_{x}$ layer is deposited at 30 (a) and $150^{\circ} \mathrm{C}$ (b) in background vacuum.

accompanied with peaks from the substrate. This indicates that PZT and LSMO are grown coherently to the STO substrates and the $\mathrm{TiO}_{x}$ films are amorphous. The $c$-axis lattice parameter of $\mathrm{PZT}$, obtained from the XRD patterns, is $4.090 \AA$, greater than its bulk value $4.082 \AA$. This can be ascribed to the in-plane epitaxial strain exerted by the LSMO layer underneath. Amorphous $\mathrm{TiO}_{x}$ is a result of low deposition temperature [14]. Surface morphology of the samples was checked by AFM. All the samples show a smooth surface, with a root-mean-square roughness less than $3.0 \AA$. A representative example is shown in Figure 1(b), where the top $\mathrm{TiO}_{x}$ layer was deposited at $80^{\circ} \mathrm{C}$ in $2.0 \mathrm{~Pa}$ oxygen. Figure 1(c) shows the ferroelectric hysteresis loop of a $50 \mathrm{~nm}$ PZT film. The coercive voltage is about $3.0 \mathrm{~V}$ and the remnant polarization is about $40 \mu \mathrm{C} / \mathrm{cm}^{2}$, in agreement with those reported in the literature $[15,16]$.

Current-voltage $(I-V)$ characteristics of Pt/PZT/LSMO heterostructures are shown in Figure 2(a). The voltage was set to sweep from $0 \mathrm{~V}$ to $10.0 \mathrm{~V}$, then from $10.0 \mathrm{~V}$ to $-10.0 \mathrm{~V}$, and finally from $-10.0 \mathrm{~V}$ back to $0 \mathrm{~V}$. Pronounced bipolar resistive switching can be observed. The device is initially in the high resistance (low current) state. It is switched to a low resistance (high current) state when the voltage exceeds about $3.2 \mathrm{~V}$. When negative voltages are applied, the device behaves in a similar way, switching from the high resistance state to the low resistance state at about $-3.4 \mathrm{~V}$. Note that the resistance state switches at the coercive voltage of the PZT film. Figures 2(b)-2(e) show $I-V$ curves of $\mathrm{Pt} / \mathrm{TiO}_{x} / \mathrm{PZT} / \mathrm{LSMO}$ heterostructures, in which the $\mathrm{TiO}_{x}$ layer was deposited at various temperatures in $2.0 \mathrm{~Pa}$ oxygen. In Figure 2(b), when the $\mathrm{TiO}_{x}$ layer is deposited at $30^{\circ} \mathrm{C}$, the resistance switching behavior of $\mathrm{Pt} / \mathrm{TiO}_{x} / \mathrm{PZT} / \mathrm{LSMO}$ is similar to that of Pt/PZT/LSMO. The inset of Figure 2(b) shows the $I-V$ curves of the same device, measured after poling the PZT layer by a 10.0 or a $-10.0 \mathrm{~V}$ pulse. Rectifying characteristics, switched by the poling voltage, are observed. This is a typical ferroelectric diode behavior, in which the resistance, read by a certain positive or negative voltage, is controlled by the polarization direction in the ferroelectric layer $[17,18]$. However, the resistance switching behavior varies with the increase of $\mathrm{TiO}_{x}$ deposition temperature. When the $\mathrm{TiO}_{x}$ deposition temperature is above $150^{\circ} \mathrm{C}$, the device exhibits an initial low resistance state, which can be switched into a high resistance state when the voltage exceeds $6.8 \mathrm{~V}$. This high resistance state can be maintained until a negative voltage stronger than $-5.5 \mathrm{~V}$ is applied, at which the device is reset to the low resistance state. Similar resistance switching sequence is observed in $\mathrm{Pt} / \mathrm{TiO}_{x} / \mathrm{LSMO}$ heterostructures, as shown in Figure 2(f). This is typical for bipolar resistance switching observed in $\mathrm{NiO}, \mathrm{Ta}_{2} \mathrm{O}_{5}$ and $\mathrm{TiO}_{2}$ [19-21], which is ascribed to the formation and rupture of conductive filaments [6].

These observations indicate an evolution of the resistive switching behavior from an interface controlled to a bulkcontrolled mechanism, by increasing the deposition temperature of $\mathrm{TiO}_{x}$ layers. It has been reported, in $\mathrm{TiO}_{x}$ films, that oxygen deficiency might be enhanced at elevated deposition temperatures [22]. Therefore, the conductive filaments in $\mathrm{TiO}_{x} / \mathrm{PZT}$ heterostructures may probably be formed by oxygen vacancies. In heterostructures where the $\mathrm{TiO}_{x}$ layers are deposited at 30 and $80^{\circ} \mathrm{C}$, the initial high resistance state may be a result of the highly resistive PZT layer. With increasing $\mathrm{TiO}_{x}$ deposition temperature, the concentration of oxygen vacancies increases. These charged defects may diffuse into PZT during deposition and form the conductive filaments. Therefore, the initial state becomes a low resistance state. When a positive voltage is applied, more oxygen vacancies are driven into PZT and the diameter of the filaments may grow. However, Joule heating at positive high voltages may fuse the conductive filaments and set the device into a high resistance state. When excessive oxygen vacancies are driven back into $\mathrm{TiO}_{x}$ by a negative voltage, the conductive path in PZT may be formed again. This resets the device into the low resistance state. 


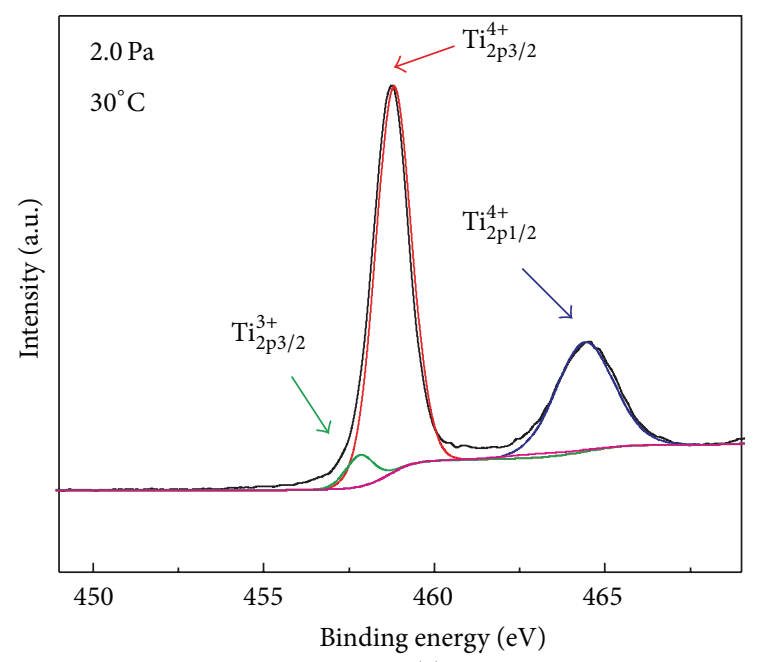

(a)

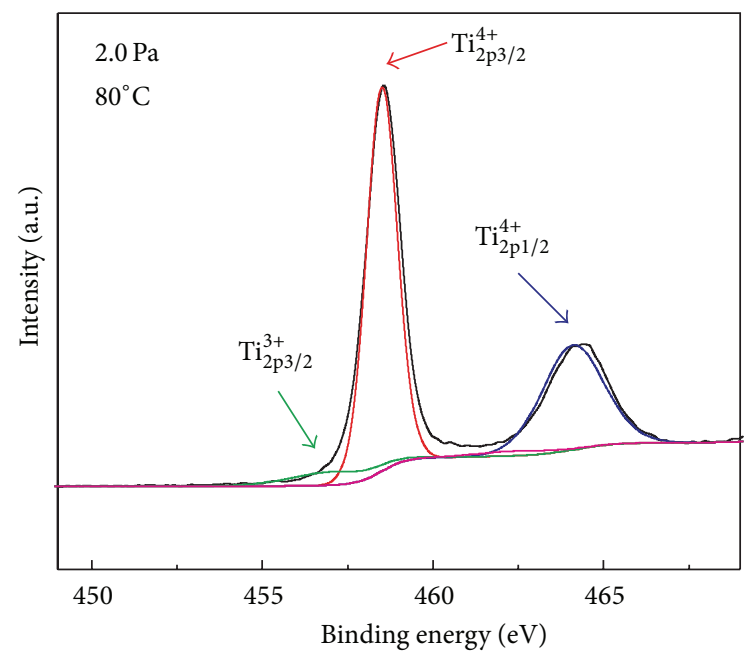

(b)

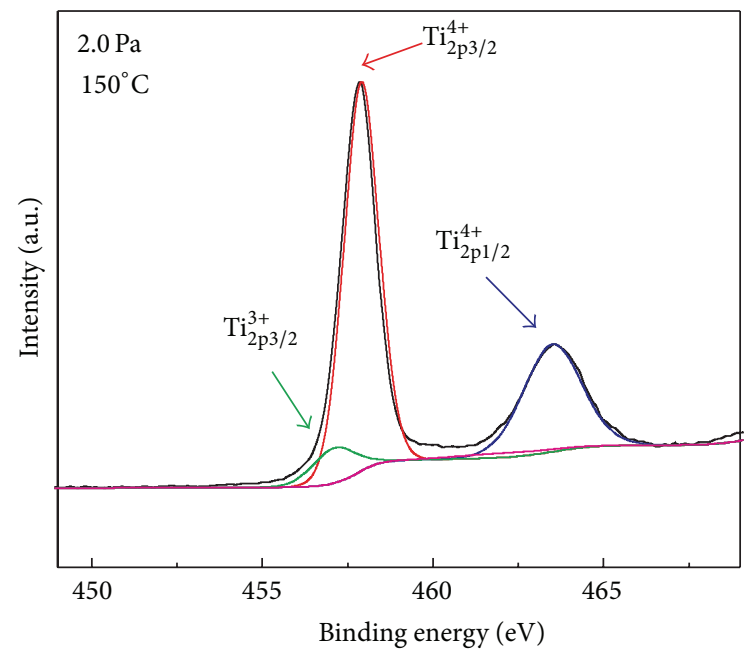

(c)

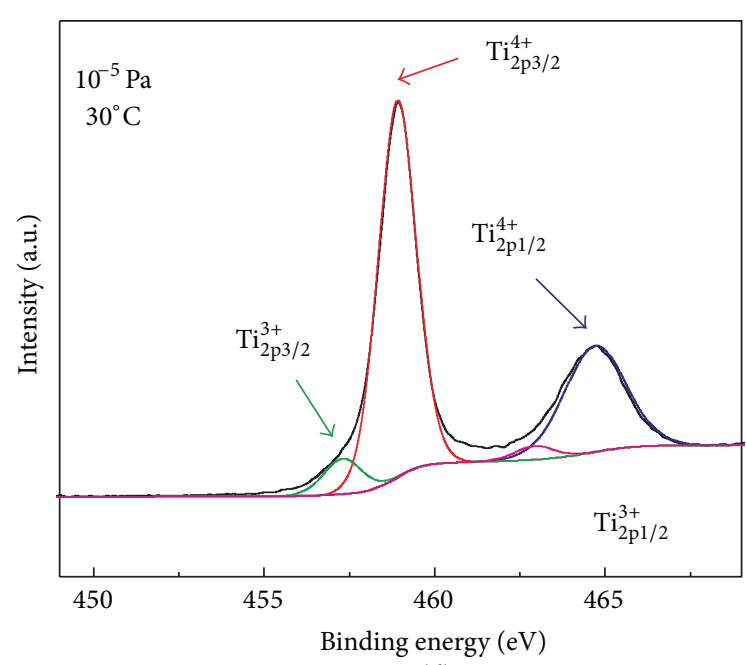

(d)

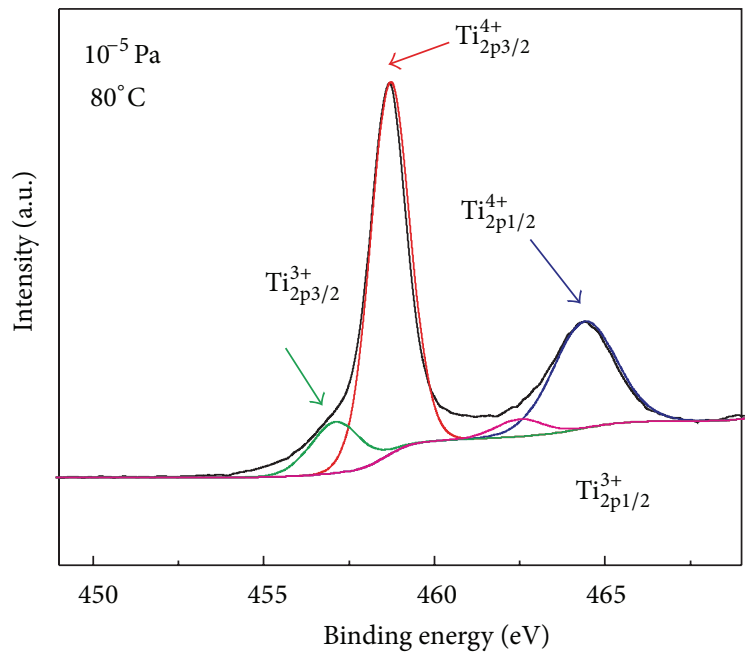

(e)

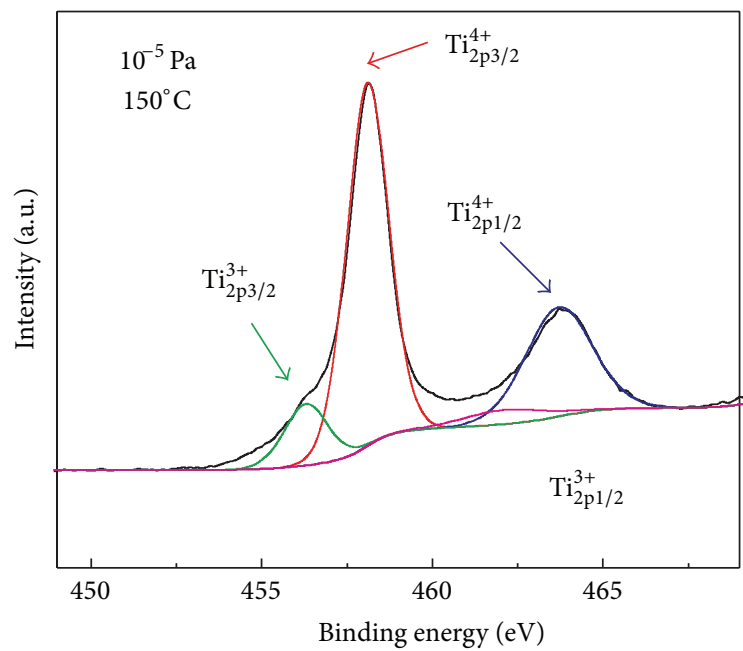

(f)

FIgURE 4: XPS spectra of $\mathrm{Ti}_{2 \mathrm{p}}$ photoemissions in $\mathrm{TiO}_{x}$ deposited at $30(\mathrm{a}, \mathrm{d}), 80(\mathrm{~b}, \mathrm{e})$, and $150^{\circ} \mathrm{C}(\mathrm{c}, \mathrm{f})$ in $2.0 \mathrm{~Pa}$ oxygen pressure (a-c) and in background vacuum $(\mathrm{d}-\mathrm{f})$. 


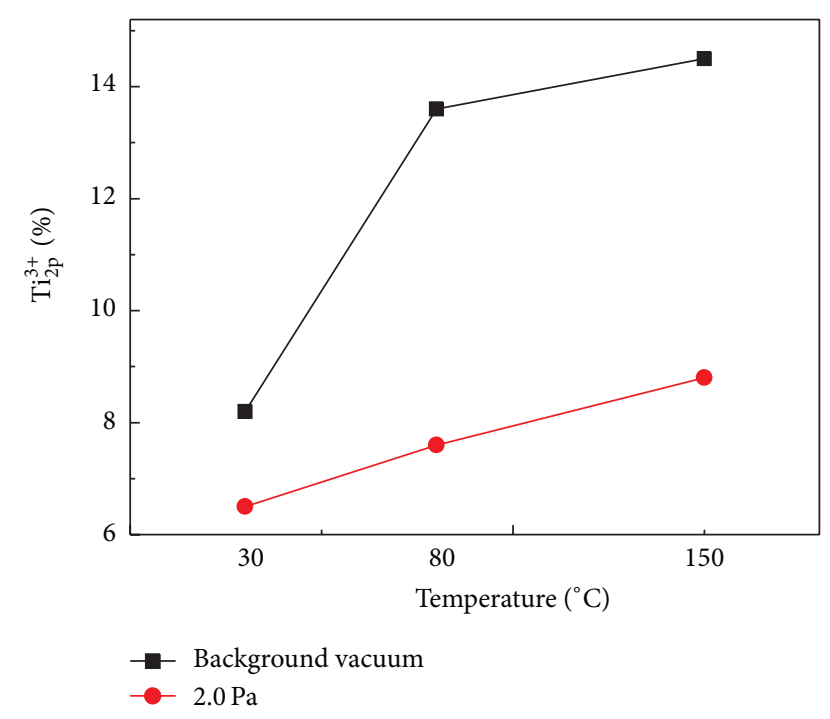

FIgURE 5: The percentage of $\mathrm{Ti}_{2 \mathrm{p}}^{3+}$ components as functions of $\mathrm{TiO}_{x}$ deposition parameters.

To check the assumption that the observed resistance switching behavior is associated with oxygen vacancies in $\mathrm{TiO}_{x}, \mathrm{TiO}_{x}$ layers were deposited on top of PZT in background vacuum to increase the oxygen vacancy concentration deliberately. As shown in Figure 3(a), the resistance switching behavior follows the conductive filament picture with an initial low resistance state, when the $\mathrm{TiO}_{x}$ layer is deposited at $30^{\circ} \mathrm{C}$. This is in contrast to the ferroelectric diode behavior observed in the device with the $\mathrm{TiO}_{x}$ layer deposited in flowing oxygen at $30^{\circ} \mathrm{C}$ (Figure 2(b)). When the deposition temperature is increased to $150^{\circ} \mathrm{C}$, no resistance switching behavior is observed due to the low resistance of the overall heterostructure, as shown in Figure 3(b). These indicate that low chamber oxygen pressure and high $\mathrm{TiO}_{x}$ deposition temperature indeed introduce more oxygen vacancies into the heterostructure.

XPS analysis was performed on various $\mathrm{TiO}_{x} / \mathrm{PZT} / \mathrm{LSMO}$ heterostructures to study the valance states of $\mathrm{Ti}$ ions in $\mathrm{TiO}_{x}$. Photoelectron spectra emitted from $\mathrm{Ti}_{2 \mathrm{p}}$ orbital are shown in Figure 4. Major features are two peaks at 458.5 and $464.1 \mathrm{eV}$, which can be assigned to the spin-orbital split of $\mathrm{Ti}_{2 \mathrm{p}}^{4+}$ orbital. The $\mathrm{Ti}_{2 \mathrm{p} 1 / 2}$ and $\mathrm{Ti}_{2 \mathrm{p} 3 / 2}$ split is $5.6 \mathrm{eV}$ and the intensity ratio is about $2: 1$. These are in agreement with previous reports on $\mathrm{TiO}_{2}[23,24]$. However, photoelectron emissions from $\mathrm{Ti}^{3+}$ ions appear at binding energies $1.4 \mathrm{eV}$ lower than their $\mathrm{Ti}^{4+}$ counterparts. The appearance of reduced Ti ions implies the existence of oxygen vacancies. It is also observable that the intensity of $\mathrm{Ti}^{3+}$ components increases with increasing deposition temperature and decreasing oxygen pressure during $\mathrm{TiO}_{x}$ deposition. Therefore, the oxygen vacancy concentration increases accordingly. As summarized in Figure 5, the $\mathrm{Ti}^{3+}$ components increase from $6.5 \%$ to $8.8 \%$ in $\mathrm{TiO}_{x}$ deposited in $2.0 \mathrm{~Pa}$ oxygen when deposition temperature increases from 30 to $150^{\circ} \mathrm{C}$. For $\mathrm{TiO}_{x}$ deposited at $80^{\circ} \mathrm{C}$, the $\mathrm{Ti}^{3+}$ percentage is 1.8 times greater in samples deposited in background vacuum than those deposited in 2.0 Pa oxygen.

\section{Conclusions}

In summary, resistive switching characteristics of $\mathrm{Pt} / \mathrm{TiO}_{x} /$ PZT/LSMO heterostructures have been studied. An evolution from an interface controlled ferroelectric diode behavior to a bulk-controlled conductive filament behavior has been observed by modulating the oxygen vacancy concentration in the $\mathrm{TiO}_{x}$ layer, which increases with increasing deposition temperature and decreasing oxygen pressure. In heterostructures with less oxygen vacancies, the PZT layers are highly resistive and the electrical transport is limited by electron injection from the interface Schottky barrier, which can be controlled by polarization switching in PZT. However, in heterostructures with more oxygen vacancies, the diffusion of oxygen vacancies into PZT results in a resistive switching behavior controlled by the formation and rupture of conductive filaments composed of conglomerated oxygen vacancies. These observations suggest that the resistive switching characteristics of bilayer heterostructures could be tuned by deposition parameters.

\section{Conflict of Interests}

The authors declare that there is no conflict of interests regarding the publication of this paper.

\section{Acknowledgments}

This work was jointly sponsored by State Key Program for Basic Research of China (2015CB921203), Natural Science Foundation of China (51222206 and 11374139), Jiangsu Provincial Natural Science Foundation (BK2012016), and Doctoral Foundation of Chinese Ministry of Education (20110091110013).

\section{References}

[1] B. Lee and H.-S. P. Wong, "Fabrication and characterization of nanoscale $\mathrm{NiO}$ resistance change memory (RRAM) cells with confined conduction paths," IEEE Transactions on Electron Devices, vol. 58, no. 10, pp. 3270-3275, 2011.

[2] D. S. Jeong, R. Thomas, R. S. Katiyar et al., "Emerging memories: resistive switching mechanisms and current status," Reports on Progress in Physics, vol. 75, no. 7, Article ID 076502, 2012.

[3] A. C. Torrezan, J.-P. Strachan, G. Medeiros-Ribeiro, and R.-S. Williams, "Sub-nanosecond switching of a tantalum oxide memristor," Nanotechnology, vol. 22, no. 48, Article ID 485203, 2011.

[4] C. H. Tu, C. C. Chang, C. H. Wang et al., "Resistive memory devices with high switching endurance through single filaments in Bi-crystal CuO nanowires," Journal of Alloys and Compounds, vol. 615, pp. 754-760, 2014.

[5] S. Park, J. Noh, M.-L. Choo et al., "Nanoscale RRAMbased synaptic electronics: toward a neuromorphic computing device," Nanotechnology, vol. 24, no. 38, Article ID 384009, 2013.

[6] G.-S. Park, Y. B. Kim, S. Y. Park et al., "In situ observation of filamentary conducting channels in an asymmetric $\mathrm{Ta}_{2} \mathrm{O}_{5-x} / \mathrm{TaO}_{2-x}$ bilayer structure," Nature Communications, vol. 4, article 2382, 2013. 
[7] I. Salaoru, T. Prodromakis, A. Khiat, and C. Toumazou, "Resistive switching of oxygen enhanced $\mathrm{TiO}_{2}$ thin-film devices," Applied Physics Letters, vol. 102, no. 1, Article ID 013506, 2013.

[8] P. Bousoulas, I. Michelakaki, and D. Tsoukalas, "Influence of oxygen content of room temperature $\mathrm{TiO}_{2-x}$ deposited films for enhanced resistive switching memory performance," Journal of Applied Physics, vol. 115, no. 3, Article ID 034516, 2014.

[9] Q. Liu, W. H. Guan, S. B. Long, R. Jia, M. Liu, and J. N. Chen, "Resistive switching memory effect of $\mathrm{ZrO}_{2}$ films with $\mathrm{Zr}^{+}$ implanted," Applied Physics Letters, vol. 92, no. 1, Article ID 012117, 2008.

[10] Y. T. Li, S. B. Long, H. B. Lv et al., "Improvement of resistive switching characteristics in $\mathrm{ZrO}_{2}$ film by embedding a thin $\mathrm{TiO}_{x}$ layer," Nanotechnology, vol. 22, no. 25, Article ID 254028, 2011.

[11] J. Park, K. P. Biju, S. Jung et al., "Multibit operation of $\mathrm{TiO}_{x^{-}}$ based ReRAM by schottky barrier height engineering," IEEE Electron Device Letters, vol. 32, no. 4, pp. 476-478, 2011.

[12] T. Choi, S. Lee, Y. J. Choi, V. Kiryukhin, and S.-W. Cheong, "Switchable ferroelectric diode and photovoltaic effect in $\mathrm{BiFeO}_{3}$," Science, vol. 324, no. 5923, pp. 63-66, 2009.

[13] J. M. Luo, S. H. Chen, S. L. Bu, and J. P. Wen, "Resistive switching and Schottky diode-like behaviors in $\mathrm{Pt} / \mathrm{BiFeO}_{3} / \mathrm{ITO}$ devices," Journal of Alloys and Compounds, vol. 601, pp. 100-103, 2014.

[14] R. Kužel, L. Nichtová, Z. Matěj, and J. Musil, "In-situ X-ray diffraction studies of time and thickness dependence of crystallization of amorphous $\mathrm{TiO}_{2}$ thin films and stress evolution," Thin Solid Films, vol. 519, no. 5, pp. 1649-1654, 2010.

[15] A. Ruiz, D. Mukherjee, J. Devkota et al., "Enhanced giant magneto-impedance effect in soft ferromagnetic amorphous ribbons with pulsed laser deposition of cobalt ferrite," Journal of Applied Physics, vol. 113, no. 17, Article ID 17A323, 2013.

[16] X. Z. Shang, H. Liu, J. Guo, D. Jiang, T. Zhou, and Y. He, "Enhancing the properties of high-temperature $\mathrm{BiScO}_{3}-\mathrm{PbTiO}_{3}$ piezoceramics via Bi addition," Materials Research Bulletin, vol. 48, no. 9, pp. 3072-3076, 2013.

[17] A. Q. Jiang, C. Wang, K. J. Jin et al., "A resistive memory in semiconducting $\mathrm{BiFeO}_{3}$ thin-film capacitors," Advanced Materials, vol. 23, no. 10, pp. 1277-1281, 2011.

[18] C. Wang, K. Jin, Z. Xu et al., "Switchable diode effect and ferroelectric resistive switching in epitaxial $\mathrm{BiFeO}_{3}$ thin films," Applied Physics Letters, vol. 98, Article ID 192901, 2011.

[19] M.-J. Lee, C.-B. Lee, D. Lee et al., "A fast, high-endurance and scalable non-volatile memory device made from asymmetric $\mathrm{Ta}_{2} \mathrm{O}_{5-x} / \mathrm{TaO}_{2-x}$ bilayer structures," Nature Materials, vol. 10, no. 8, pp. 625-630, 2011.

[20] S. Mitra, S. Chakraborty, and K. S. R. Menon, "Study of anticlockwise bipolar resistive switching in $\mathrm{Ag} / \mathrm{NiO} / \mathrm{ITO}$ heterojunction assembly," Applied Physics A: Materials Science and Processing, vol. 115, no. 4, pp. 1173-1179, 2014.

[21] M. Fujimoto, H. Koyama, M. Konagai et al., “ $\mathrm{TiO}_{2}$ anatase nanolayer on TiN thin film exhibiting high-speed bipolar resistive switching," Applied Physics Letters, vol. 89, no. 22, Article ID 223509, 2006.

[22] M. H. Zoellner, G. Niu, J.-H. Jhang et al., "Temperaturedependent reduction of epitaxial $\mathrm{Ce}_{1-x} \mathrm{Pr}_{x} \mathrm{O}_{2-\delta}(x=0-1)$ thin films on $\mathrm{Si}(111)$ : a combined temperature-programmed desorption, X-ray diffraction, X-ray photoelectron spectroscopy, and raman study," Journal of Physical Chemistry C, vol. 117, no. 47, pp. 24851-24857, 2013.
[23] J. Zhang, Q. T. Li, S. Q. Li et al., "An efficient photoanode consisting of $\mathrm{TiO}_{2}$ nanoparticle-filled $\mathrm{TiO}_{2}$ nanotube arrays for dye sensitized solar cells," Journal of Power Sources, vol. 268, pp. 941-949, 2014.

[24] G. Marcì, V. Augugliaro, M. J. López-Muñoz et al., "Preparation characterization and photocatalytic activity of polycrystalline $\mathrm{ZnO} / \mathrm{TiO}_{2}$ systems. 1. Surface and bulk characterization," The Journal of Physical Chemistry B, vol. 105, no. 5, pp. 1026-1032, 2001. 

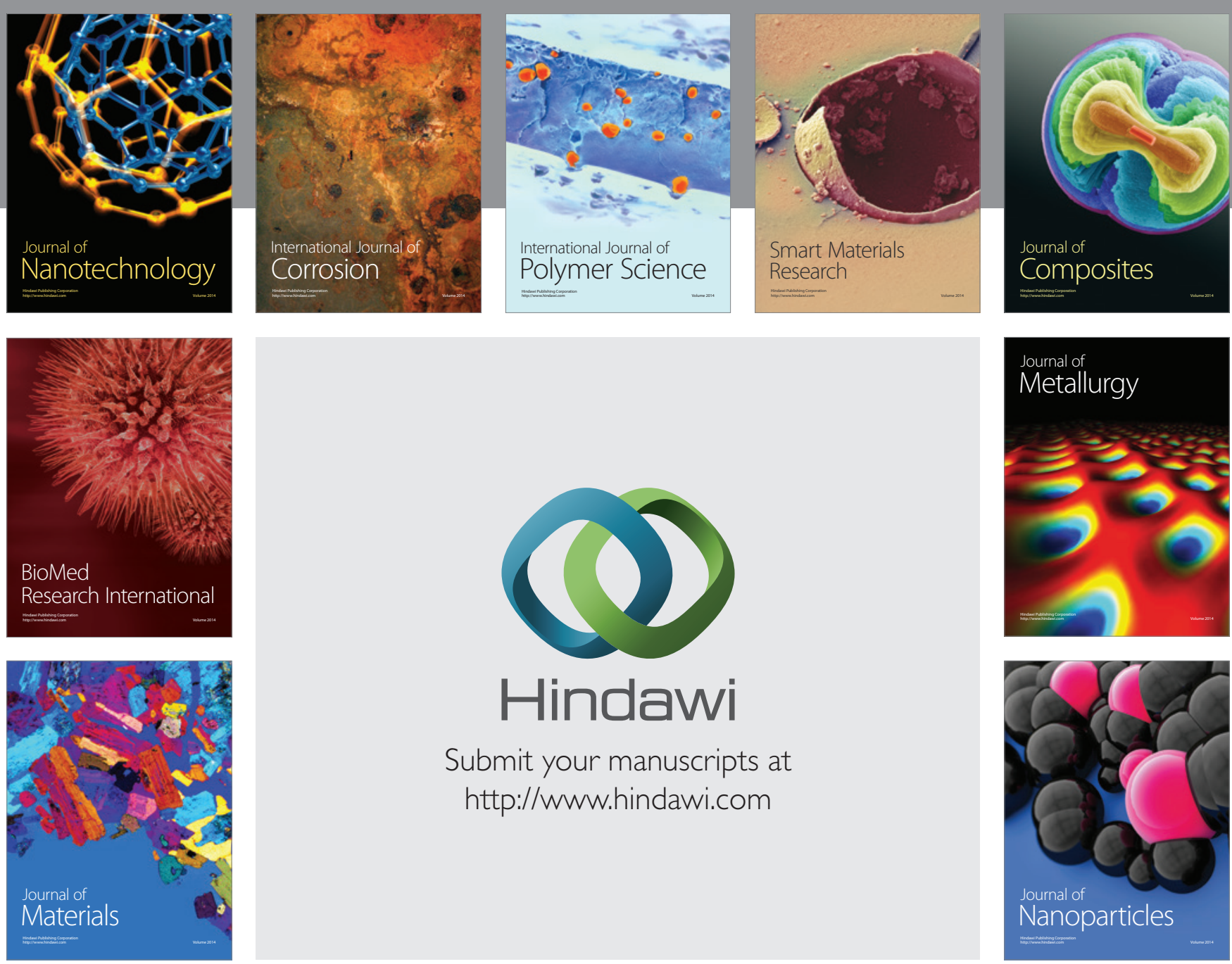

Submit your manuscripts at http://www.hindawi.com
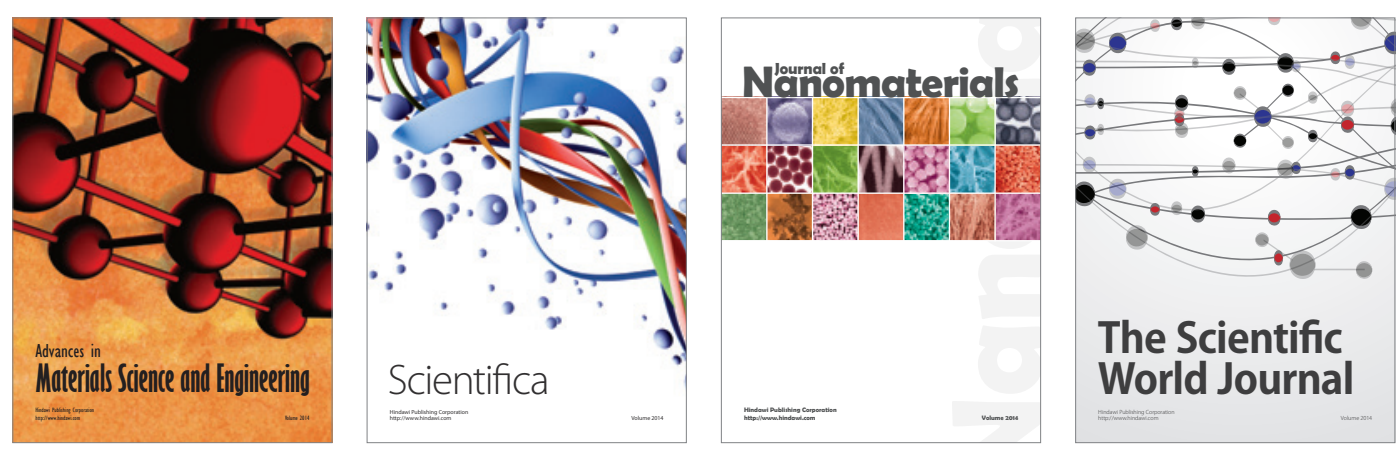

\section{The Scientific World Journal}
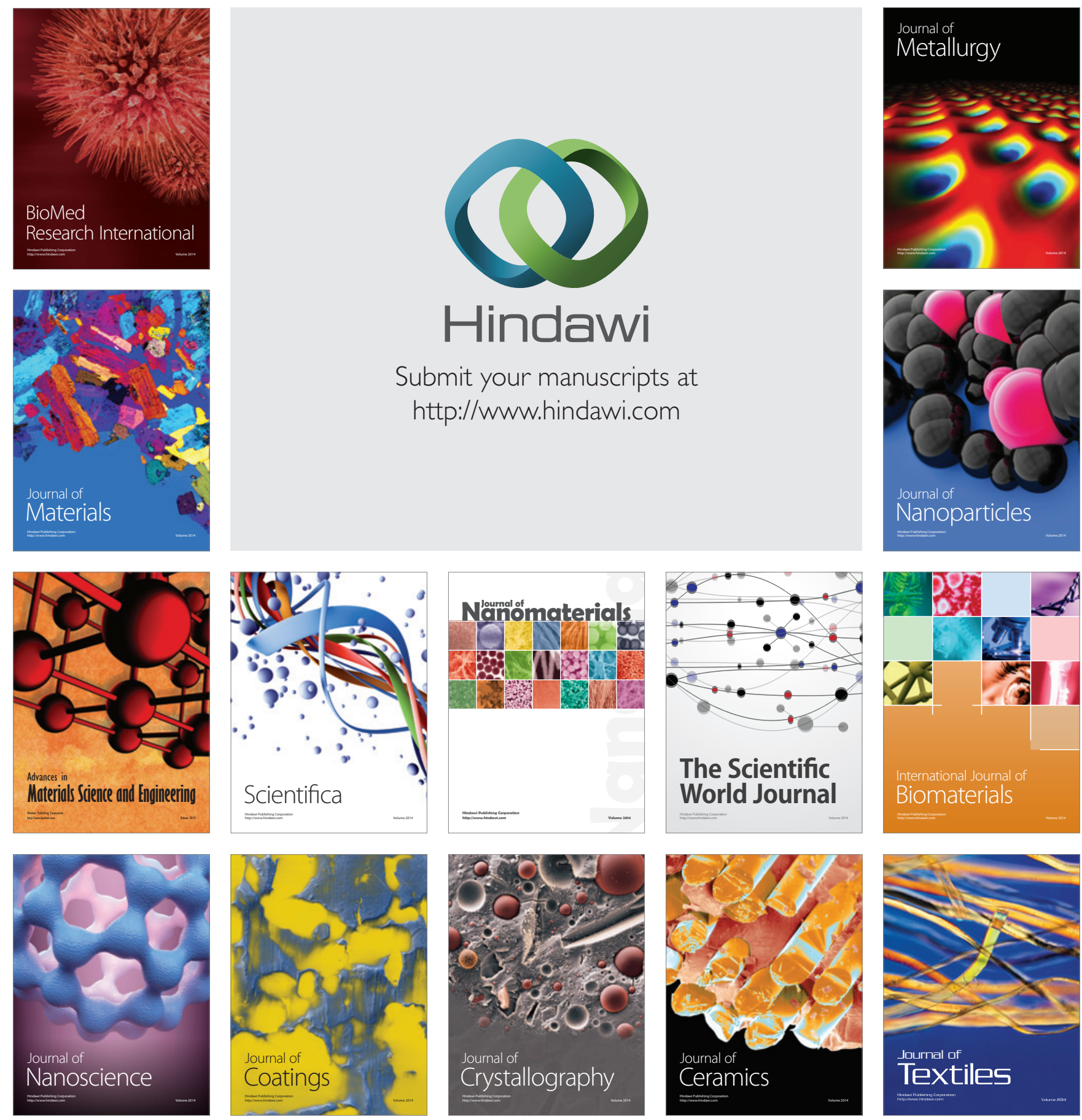